\title{
Testing measurements of airflow velocity in road tunnels
}

\author{
Peter Danišovič ${ }^{1, *}$, Juraj Srámek $^{1}$, Michal Hodoň ${ }^{2}$ and Martin Húdik ${ }^{2}$ \\ ${ }^{1}$ University of Žilina, Faculty of Civil Engineering, Department of Construction Management, \\ Univerzitná 8215/1, 01026 Žilina, Slovakia \\ ${ }^{2}$ University of Žilina, Faculty of Management Science and Informatics, Department of Technical \\ Cybernetics, Univerzitná 8215/1, 01026 Žilina, Slovakia
}

\begin{abstract}
Within the project entitled "Models of formation and spread of fire to increase safety of road tunnels", it was necessary to devise a method how to record airflow velocity during the fire in situ tests in road tunnels. Project is in first year of its solution so one testing measurement was performed to check the functionality of anemometers selected for this project and the first in situ measurement was also performed just a few days ago.
\end{abstract}

\section{Introduction}

Fires in road tunnels are the most unfavourable emergency events with catastrophic consequences in enormous material damages and sometimes in losses of human lives. Several recent fires in the last 20 years have shown warning message for humanity and the need to deal with smoke behaviour during the fire in road tunnel. The lack of information about an active fire is one of the most important factors leading to fatal tragic incidents which can be partially eliminated by computer simulation. The aim of applied research project mentioned in the abstract is, among other things, to perform two in situ fire simulations. For these reasons we had to devise a method of airflow velocity recording during the fire simulations because this is extremely important to know the progress of airflow velocity, the change of airflow direction and time of smoke stratification disturbing. Before first in situ fire simulation we decided to check our anemometers in the longest Slovak road tunnel. The first in situ fire simulation was performed a few days ago. The methods of measurements are described in this paper.

\section{Testing and calibration}

Before the first measurement we create own wind tunnel (Fig. 1) to calibrate anemometers, test connection and way of power supply and data recording to flash memory (microSD card).

\footnotetext{
*Corresponding author: peter.danisovic@fstav.uniza.sk
} 


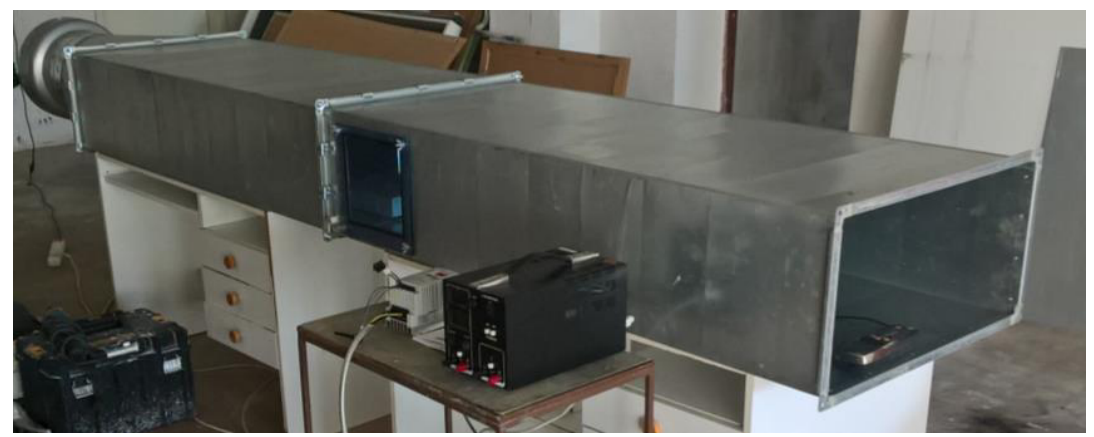

Fig. 1. Wind tunnel for testing and calibration of anemometers.

\subsection{Testing measurement}

First testing measurement was performed in the longest road tunnel of Slovakia (up to $5 \mathrm{~km}$ long). It is one tube tunnel with bi-directional traffic and semi-transversal ventilation system (Fig. 2). This system uses air ducts to introduce inside the tunnel set flow rates of fresh air so to accomplish the dilution of the pollutants [1]. During normal operation pollutants can be also extracted by ventilation chimney located in the heart of the tunnel. In case of fire, the fans need to be able to reverse their running direction so to extract the smoke flow rate and grant safe environment to the tunnel users [1]. The contaminated air or fire smoke is extracted through the open air flaps in the tunnel intercooling. With the correct fire scenario, 5 ventilation flaps open in the vicinity of the fire, then the contaminated air spreads in ventilation duct separated from traffic environment.

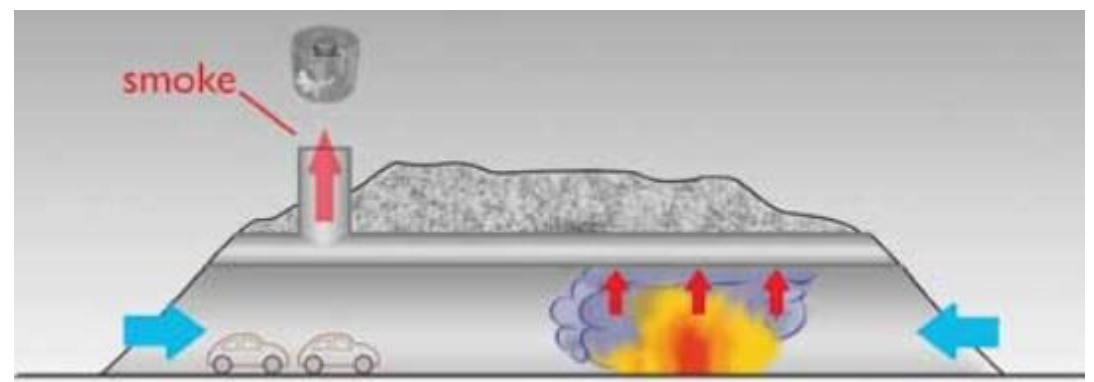

Fig. 2. Principle of semi-transversal ventilation system [1].

Our testing measurement was positioned to the ventilation duct to verify the airflow velocity and the required volume rate of airflow produced by fans located in the chimney. There may be some losses from leakage of ventilation system (ventilation flaps which should be closed). We placed 5 anemometers (Fig. 3) in the vicinity of the expected opening of the 5 ventilation flaps based on the location of the simulated fire source (Fig. 4). 


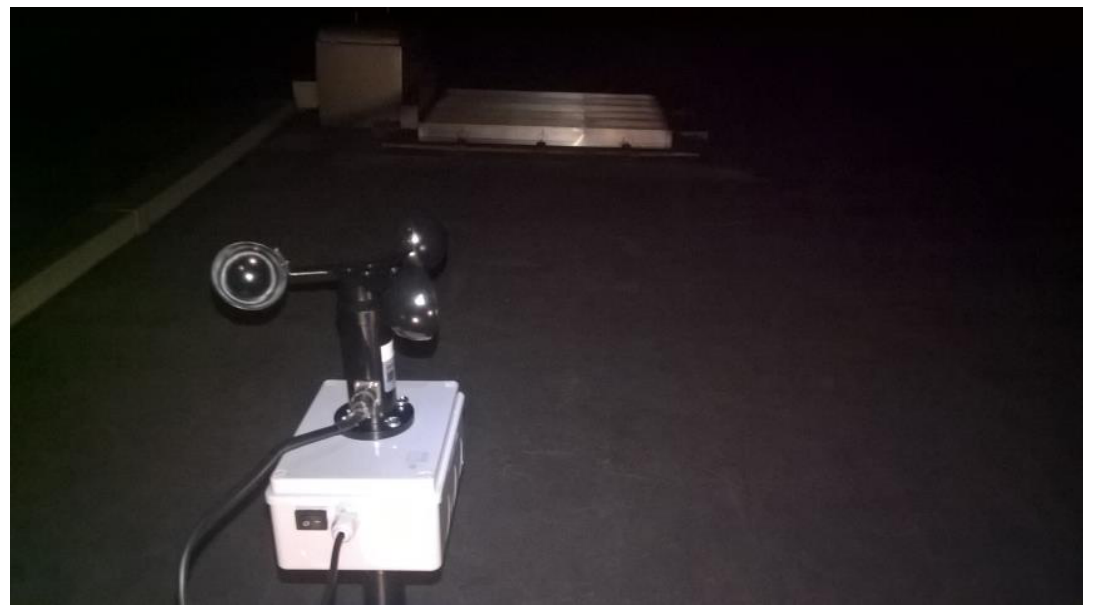

Fig. 3. Anemometer in ventilation duct (ventilation flap in the background).

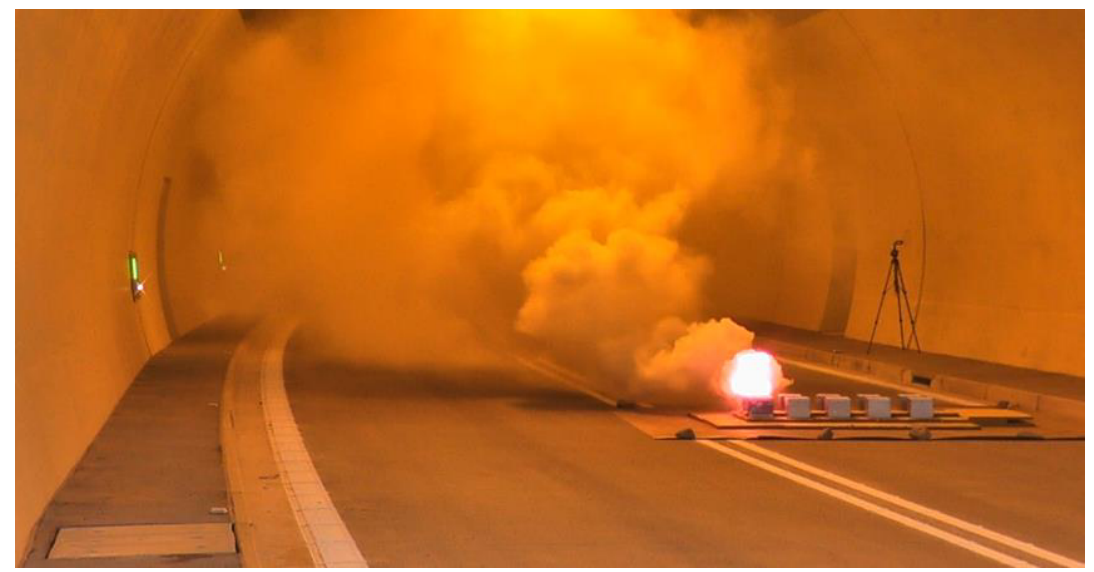

Fig. 4. Simulated fire (an action member of fire scenario).

An expected scenario did not occur because fire alarm was activated in the next zone as expected. Six ventilation flaps were opened and only two of our predicted flaps. A maximum speed of about 17 meters per second was measured. Ventilation fans placed in chimney have output volume totally about $188 \mathrm{~m}^{3} . \mathrm{s}^{-1}$ so in the cross section of ventilation duct about $14 \mathrm{~m}^{2}$ it is very good result of airflow velocity extraction. Airflow velocity was measured in the middle of ventilation duct and 1,1 $\mathrm{m}$ above the ground.

\section{PROJECT EXPERIMENT IN SITU}

Research of proper method of parallelisation of simulation calculation with the aim to achieve substantial speedup of calculation without negative effect on the calculation accuracy, research on the impact of ventilation on stratification of smoke in tunnel tube and realization of experiments in two road tunnels in situ are the main parts of the project [2]. Two full-scale fire experiments in an one tube and two tube tunnel are planned during the project solution. First experiment was performed in a tunnel Pol'ana (bidirectional traffic) just only one week ago. Tunnel is about $900 \mathrm{~m}$ long with a longitudinal ventilation system consisting of four couples of jet fans. In cooperation with company KBK fire we prepared experiment based on "cold smoke" (aerosol, Fig. 4) focused on the smoke stratification 
investigation and the impact of ventilation on maintaining and disruption of stratification. For this reason, 2 mobile anemometric networks (one consisting of 9 anemometers and 2 potentiometric wind-vanes, Fig. 5), 2 separate anemometers along with potentiometric wind-vanes (Fig. 6) and 3 optical gates (Fig. 7) were efficiently located in the tunnel.

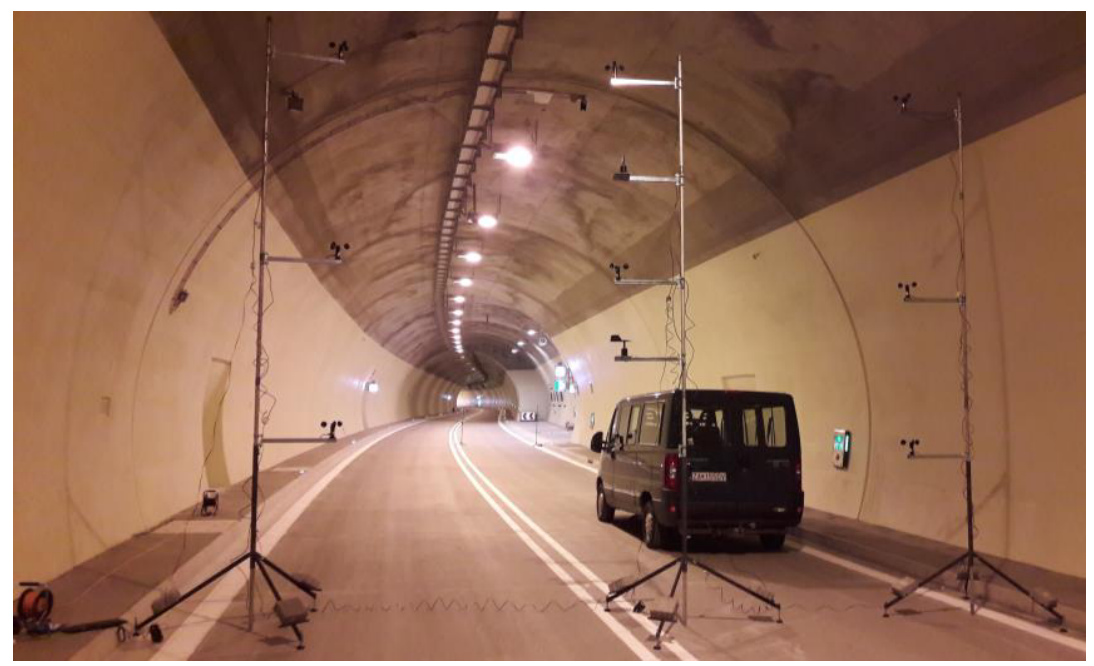

Fig. 5. Mobile anemometric network for measuring air flow velocity and direction in tunnels.

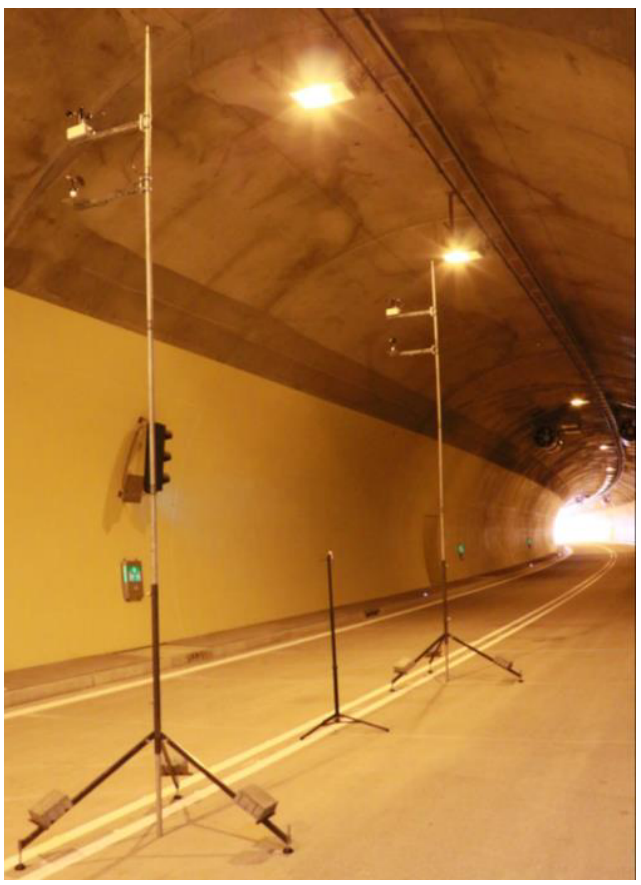

Fig. 6. Two separate anemometers located behind the end of lay-by in direction of presupposed airflow. 


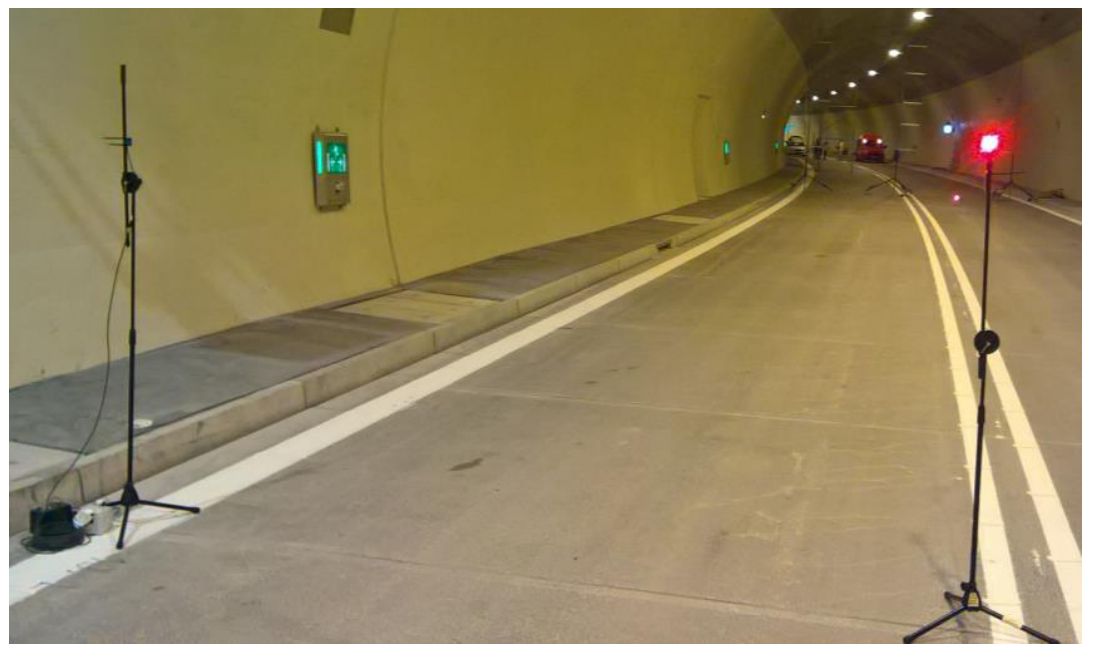

Fig. 7. Optical gate installed at the beginning of lay-by.

All measuring equipment were efficiently located (Fig. 8), it means that the anemometric mobile networks were located before and behind the source of aerosol just under the real tunnel anemometers (blocks n. 39 and 47) to compare the measured values. The optical gates and separate anemometers were arranged before and behind lay-by (blocks n. 36, 54 and 58) because this is the place of smoke stratification problems as shown initial computer simulations of automobile fire in the middle of the tunnel Pol'ana between two emergency lay-bys presented in [3].

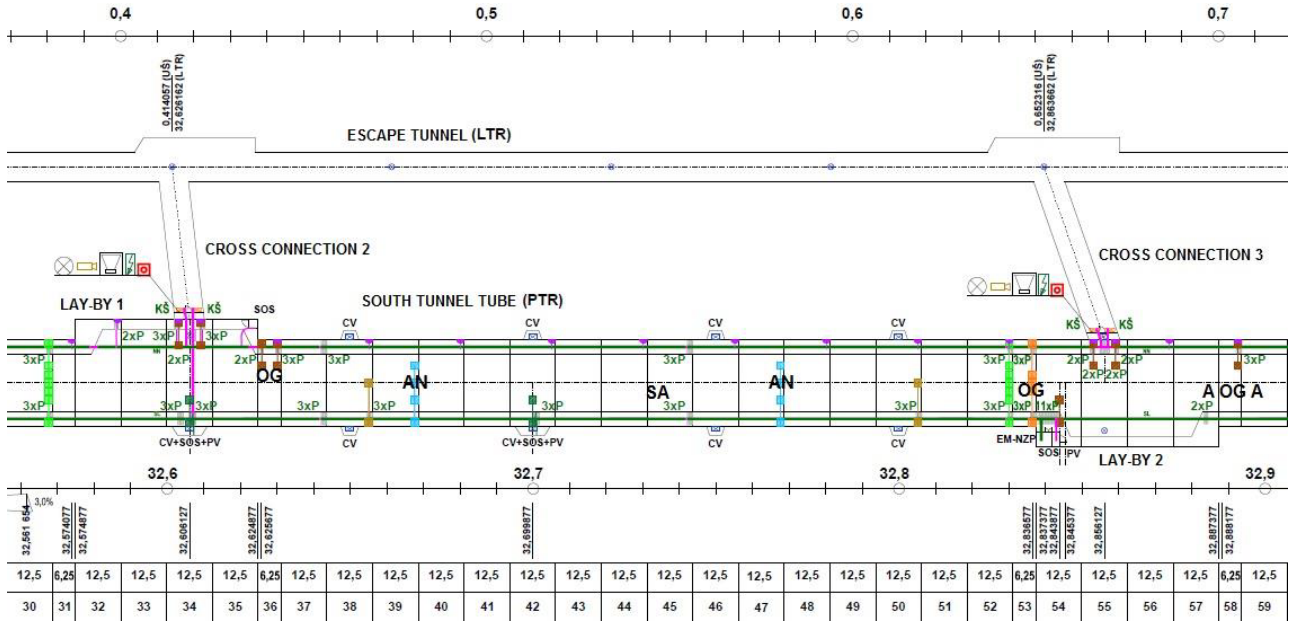

Fig. 8. Location of measuring equipment. Legend: $\mathrm{OG}$ - optical gate, $\mathrm{AN}$ - anemometric network, $\mathrm{SA}$ - source of aerosol, A - separate anemometer

\section{Conclusion}

In this paper specific measurements of airflow velocity in different road tunnels are illustrated. Measured values in tunnel Pol'ana will be used for verification of smoke spread and stratification computer simulations. The aim of the project is to develop a series of computer simulations of selected types of fires in road tunnels and in the virtual tunnel of 
Tunnel Traffic \& Operation Simulator which can be used as a didactic tool for visualisation of the smoke stratification.

This work was supported by the Slovak Research and Development Agency APVV (project No. APVV-15-0340).

\section{References}

1. Tunnel Ventilation. Business Area Tunnel Fans. Catalogue of Systemair S.p.A (2012)

2. Models of formation and spread of fire to increase safety of road tunnels. Basic information on the project APVV-15-0340 (2015)

3. P. Danisovic, J. Glasa, P. Weisenpacher, L. Valasek, Models of formation and spread of fire to increase safety of road tunnels. XXVI Polish - Russian - Slovak Seminar TFOCE (to be published) 